\title{
Long-term outcome of head injuries: a 23 year follow up study of children with head injuries
}

\author{
Harry Klonoff, Campbell Clark, Pamela S Klonoff
}

Abstract

The purpose of the 23 year follow up study was to determine the relationship between trauma variables including measures of head injury and very long-term sequelae. The study included 159 individuals with a mean age 31.40 years, of whom approximately $90 \%$ were admitted to hospital with a mild head injury during childhood (mean age 7.96). Extent of head injury was determined by unconsciousness, neurological status, skull fracture, EEG, post-traumatic seizures and a composite measure. The composite measure of neurological variables was the best predictor of long-term outcome. In addition, IQ recorded in the postacute phase was a reliable predictor of long-term outcome. Of the sample, $32.7 \%$ reported physical complaints and $17 \cdot 6 \%$ reported current psychological/ psychiatric problems unrelated to the head injury. Subjective sequelae (physical, intellectual and emotional) specified as due to the head injury were reported by $31 \%$ of the sample, and the sequelae were found to be related to the extent of the head injury and initial IQ. There were no discernible relationships between attribute variables including premorbid status and age with subjective sequelae. There were, however, significant relationships between subjective sequelae and objective, psychosocial measures of adaptation including educational lag, unemployment, current psychological/psychiatric problems and relationships with family members. Finally, there appeared to be continuity of complaints elicited during the five year follow up of the original project and current sequelae. The severity of the head injury was identified as the primary contributory factor in the reconstitution process and in the prediction of long term outcomes.

\section{(F Neurol Neurosurg Psychiatry 1993; 56:410-415)}

Despite extensive research on the diverse effects of head injuries, particularly mild head injuries, there is a profound paucity of very long-term outcome studies in children sustaining traumatic brain injuries. In 1967 a prospective study of 231 children who sustained closed head injuries was initiated. In subsequent years a number of publications including the final results of the five year follow up study were published. ${ }^{2}$ The current study is a 23 year follow up of the children included in the original project. The purpose of the study was to determine the relationship between trauma variables including measures of extent of head injury and very long-term sequelae.

The acute neurological, cognitive, emotional and physical sequelae of closed head injury $^{34}$ including mild head injuries ${ }^{5}$ are well documented for children ${ }^{1}$ and adult ${ }^{6}$ samples.

Recent interest has focused on the short and long-term outcome following traumatic brain injury. Publications range from the subacute phase of one month after the head injury, ${ }^{7}$ to follow up for periods up to four years, ${ }^{8}$ and late outcome studies from six to 15 years post-trauma. ${ }^{9-12}$ No published study has evaluated outcome as long as 23 years after injury. In addition, no study has documented the long-term consequences of head injury from childhood to adulthood in the same patient sample.

In follow up studies, enduring neuropsychological deficits have been reported. ${ }^{6}$ Other commonly identified problems at follow up are in the areas of behavioural dysfunction, including anxiety, depression and social withdrawal. ${ }^{81314}$ Families identify the behavioural changes as the most enduring and troublesome compared with the physical and cognitive sequelae. ${ }^{9}$

Increasingly, studies have evaluated changes in work status after head injury. Results are variable; but most studies report a significant degree of unemployment or reduced work capacity. ${ }^{915-17}$ Several studies have evaluated factors affecting return to work after head injury. Decreased rates of employment have been found with increased severity of injury, as measured by length of coma, ${ }^{15}$ by initial Glasgow Coma Scale score ${ }^{8}$ and length of post-traumatic amnesia. ${ }^{18}$ Greater cognitive dysfunction has also been related to poorer vocational outcome. ${ }^{19} 20$

A growing body of literature has evaluated predictors of outcome after head injury, including severity of head injury and age at time of trauma. ${ }^{4}$ It has been suggested that children sustaining brain injuries show improved neurological and cognitive recovery compared with older age groups. ${ }^{41-23}$ One study, however, reported no significant relationship between age and outcome. ${ }^{24}$

Typically, the recovery of patients sustaining head injury has been determined by interviewer ratings. ${ }^{25}$ The best known of these is 
Table 1 Demographic characteristics of cohort at time of head injury $(n=159)$

\begin{tabular}{lr}
\hline Characteristics & \\
Age (years) & \\
Mean 7.96 & \\
SD $3 \cdot 28$ & $2 \cdot 7-15 \cdot 9$ \\
Range & $29 \cdot 6$ \\
Educational placement (\%) & $60 \cdot 3$ \\
Pre-school & $10 \cdot 1$ \\
Primary (lower secondary) & \\
Secondary (upper secondary) & $24 \cdot 5$ \\
Occupations of fathers (\%) & $44 \cdot 1$ \\
Professional and semi-professional & $27 \cdot 6$ \\
Clerical and skilled & $3 \cdot 8$ \\
Semi-skilled and unskilled & \\
Unemployed & 44 \\
Agent of injury (\%) & 48 \\
Automobile & 8 \\
Fall & $12 \cdot 7$ \\
Other & $21 \cdot 4$ \\
Length of hospitalization & $27 \cdot 0$ \\
Mean days & $26 \cdot 4$ \\
Litigation (\%) & $19 \cdot 5$ \\
Pre-morbid anomalies (\%) & $2 \cdot 5$ \\
Multiple injuries (\%) & $1 \cdot 9$ \\
Musculoskeletal & $1 \cdot 3$ \\
Abdomen & $0 \cdot 6$ \\
Ears/nose & $0 \cdot 6$ \\
Eyes & \\
Skin & \\
Respiratory & \\
\hline
\end{tabular}

the Glasgow Outcome Scale. ${ }^{26}$ Recently, research has started to focus on outcome based on patient interviews, ${ }^{8}$ and psychosocial changes in head injured adults using questionnaire data from patients compared with their families. ${ }^{27}$

\section{Methods and results}

The initial project set out to investigate prospectively a head-injured group of children from the time of trauma to the fifth year after trauma, within the context of antecedent factors (pre-morbid anomalies, age, sex), circumstances at time of head injury (extent of injury) and consequence factors (education, interpersonal transactions, sequelae). The original sample comprised 231 children-147 boys and 84 girls-with a mean age of 8.32 years at the time of the head injury. Children included in the project were consecutive admissions to two university hospitals between August 1967 and November 1968 with a diagnosis of head injury. The number

Table 2 Neurological indicators of extent of head injury (\%)

\begin{tabular}{|c|c|c|c|c|}
\hline $\begin{array}{l}\text { Loss of } \\
\text { Consciousness }\end{array}$ & $\begin{array}{l}\text { Neurological } \\
\text { status }\end{array}$ & $\begin{array}{l}\text { Skull } \\
\text { fracture }\end{array}$ & $\begin{array}{l}\text { EEG } \\
\text { rating }\end{array}$ & Seizure \\
\hline $\begin{array}{l}\text { Not proven or } \\
\text { momentary }\end{array}$ & $\begin{array}{l}\text { No clinical } \\
\text { evidence of } \\
\text { trauma }\end{array}$ & None & $\begin{array}{l}\text { Normal/ } \\
\text { Equivocal }\end{array}$ & Absent \\
\hline$(52 \cdot 2)$ & $\begin{array}{l}(24 \cdot 5) \\
\text { Unconsciousness }\end{array}$ & $(59 \cdot 7)$ & $(40 \cdot 3)$ & $(93 \cdot 7)$ \\
\hline $\begin{array}{l}5 \text { minutes to } \\
\text { less than } \\
30 \text { minutes }\end{array}$ & $\begin{array}{l}5 \text { minutes to less } \\
\text { than } 30 \text { minutes } \\
\text { or } \\
\text { concussion } \\
\text { or } \\
\text { skull fracture } \\
\text { (simple) }\end{array}$ & $\begin{array}{l}\text { Simple } \\
\text { linear }\end{array}$ & $\begin{array}{l}\text { Minimal } \\
\text { abnormal }\end{array}$ & Petit mal \\
\hline$(37 \cdot 1)$ & $\begin{array}{l}(60 \cdot 4) \\
\text { Unconsciousness }\end{array}$ & $(22 \cdot 0)$ & $(38 \cdot 4)$ & $(4 \cdot 4)$ \\
\hline $\begin{array}{l}\text { more than } \\
30 \text { minutes }\end{array}$ & $\begin{array}{l}\text { more than } \\
30 \text { minutes } \\
\text { or } \\
\text { concussion } \\
\text { or } \\
\text { skull fracture } \\
\text { (basal/depressed) } \\
\text { with } \\
\text { other symptoms } \\
\text { (for example aphasia) }\end{array}$ & $\begin{array}{l}\text { Basal/ } \\
\text { depressed }\end{array}$ & $\begin{array}{l}\text { Moderate/ } \\
\text { marked } \\
\text { abnormal }\end{array}$ & $\begin{array}{l}\text { Grand } \\
\text { mal }\end{array}$ \\
\hline$(10 \cdot 7)$ & $(15 \cdot 1)$ & $(18 \cdot 3)$ & $(21 \cdot 3)$ & $(1 \cdot 9)$ \\
\hline
\end{tabular}

of re-examinations varied among the group and 117 children were examined during the fifth year of follow up.

During 1990-91, 175 (76\%) of the individuals included in the original project were traced by a variety of means and $159(91 \%)$ volunteered to participate in the current study. Of the remaining 16 , contacts were made with parents or relatives but the member of the cohort did not return telephone calls. A university approved consent form was completed by the volunteers who were interviewed. Geographic locations of the cohort included Canada, USA, Europe, Australia and the Middle East. The senior author interviewed all the volunteers either in person $(n=82)$ or by telephone $(n=77)$. In two instances information was provided by a parent with the volunteer, while in two additional instances only the parent provided information because of the volunteer's mental status.

A standardised interview was conducted with a predetermined format. Details of the original data base obtained during admission to hospital and on follow up were unknown to the interviewer and the volunteer. Any difference therefore in subjective impressions should be randomly distributed among those with or without elicited sequelae.

Table 1 describes the demographic characteristics of the cohort of 159 adults at the time of trauma.

Although the Glasgow Coma Scale is now widely used to determine the severity of head injury, this project was conducted before its development. Therefore, four uni-dimensional neurological indexes (length of unconsciousness, skull fractures, EEG ratings ${ }^{2}$ and post-traumatic seizures) and one global measure (neurological status) were used as indicators of the extent of head injury. The last measure was derived from the medical opinion of one examiner. These variables and respective percentages are itemised in table 2 .

In addition to the ratings of each variable from 1 to 3, a composite score of 5-15 was also derived by summing the 5 variables. The composite score ranged from 5-13 with a median of 7 , with the following distribution: 5-8 (63.5\%); 9-10 (27.6\%); 11-13 (8.9\%).

The initial neuropsychological examination revealed a mean (SD) IQ of $103.0(15 \cdot 0)$, with a range from 46 to 136 . The fifth year follow up mean (SD) IQ was $111.2(11 \cdot 7)$, with a range from 77 to 137 .

Table 3 describes the current demographic and personal-social characteristics of the cohort.

\section{Health history}

Subsequent (recurrent) head injuries were reported by $15 \cdot 1 \%(8 \cdot 8 \%$ with loss of consciousness) of the sample and the number of such head injuries were as follows: $1-10 \cdot 7 \%$; $2-2.5 \% ; 3-1 \cdot 3 \% ; 4-0 \cdot 6 \%$.

Table 4 summarises the 66 intervening physical complaints (not mutually exclusive) specified by the sample as unrelated to the head injury. The physical complaints were 
Table 3 Current demographic and personal-social characteristics $(n=159)$

\begin{tabular}{lr}
\hline Characteristics & \\
Age (years) & \\
Mean & $31 \cdot 40$ \\
SD & $3 \cdot 23$ \\
Range & $25-40$ \\
Male:Female (n) & $105: 54$ \\
Education (\%) & $7 \cdot 6$ \\
Grades 7-9 (lower secondary) & $50 \cdot 3$ \\
Grades 10-12 (upper secondary) & \\
Post-secondary (tertiary & $28 \cdot 9$ \\
vocational professional) & $10 \cdot 1$ \\
Bachelors degrees & $3 \cdot 1$ \\
Post-graduate degrees & $25 \cdot 8$ \\
Grade failure (retention) (\%) & \\
Marital status (\%) & $59 \cdot 2$ \\
Married/common-law & $28 \cdot 9$ \\
Single & $11 \cdot 9$ \\
Divorced/separated & \\
Occupation (\%) & $27 \cdot 1$ \\
Professional and semi-professional & $38 \cdot 4$ \\
Clerical and skilled & $27 \cdot 6$ \\
Semi-skilled and unskilled & $4 \cdot 4$ \\
Homemaker & $2 \cdot 5$ \\
Student & \\
Employment status (\%) & $80 \cdot 1$ \\
Full time & $7 \cdot 3$ \\
Part time & $4 \cdot 4$ \\
Homemaker & $2 \cdot 5$ \\
Student & $1 \cdot 9$ \\
Disability unrelated to trauma & $3 \cdot 8$ \\
Unemployed & \\
Interpersonal relationships (\%) & $11 \cdot 9$ \\
Strained relationship with spouse & $17 \cdot 9$ \\
Strained relationship with family members & $30 \cdot 2$ \\
Leisure activities restricted (\%) & $10 \cdot 1$ \\
Alcohol problem (\%) & $4 \cdot 4$ \\
Past & $2 \cdot 6$ \\
Current & $2 \cdot 5$ \\
Illicit drug use (\%) & \\
Past social & \\
Past heavy & \\
Current social & \\
Current heavy & \\
Contact with legal authorities (\%) & \\
One criminal charge & \\
Multiple criminal charges & \\
\hline
\end{tabular}

itemised in a systems schema. ${ }^{28}$ However, some of these complaints reported by $32.7 \%$ of the sample may be related to the multiple injuries sustained at the time of the head injury or in a number of instances, subsequent head injuries. Seizures were reported by one individual who had a severe head injury in 1989 and dizzy spells were reported by another individual who had relatively severe head injuries in 1976 and 1990.

Resolved psychological/psychiatric problems specified as unrelated to the initial head injury were reported by $31.4 \%$ of the sample. The 60 reported problems (not mutually

Table 4 Physical complaints unrelated to head injury $(n=159)$

\begin{tabular}{llc}
\hline System & Complaints & Frequency \\
\hline Neurological & Seizures & 1 \\
& Dizzy spells & 1 \\
Musculo-skeletal & Leg/back pain & 20 \\
& Arthritis & 8 \\
Head and Neck & Headaches & 5 \\
& Neck pain & 3 \\
Ears/Nose & Thyroid & 2 \\
& Reduced hearing & 4 \\
Abdomen & Sinusitis & 2 \\
& Colitis & 1 \\
& Crohn's disease & 1 \\
& Hepatitis & 1 \\
Skin & Ulcers & 1 \\
Chest and Lungs & Liver & 1 \\
Lymphatic & Psoriasis/eczema & 3 \\
Heart/Blood vessels & Asthma & 8 \\
Metabolism & Lymphoma & 1 \\
\hline
\end{tabular}

exclusive) were categorised as: emotional disorders $(40.0 \%)$; problems with spouse or child (36.6\%); problems with parents (15.0\%); substance abuse $(5.0 \%)$; and relationships in general $(3.4 \%)$.

Current psychological/psychiatric problems specified as unrelated to the initial head injury were reported by $17.6 \%$ of the sample. The 33 reported problems (not mutually exclusive) were categorised as: emotional disorders $(42.4 \%)$ including one chronic schizophrenic; problems with spouse or child $(21 \cdot 2 \%)$; substance abuse $(12 \cdot 1 \%)$; problems with parents $(9 \cdot 1 \%)$; relationships in general $(9 \cdot 1 \%)$; and sleep problems $(6 \cdot 1 \%)$.

A comparison of those in the sample listing no psychological/psychiatric problems or specifying problems both in the past and the present, revealed the following: $62 \cdot 3 \%$ listed no problems at any time; $11.3 \%$ listed problems both in the past and present; $20.1 \%$ listed a problem in the past but not currently; and, $6.3 \%$ did not list a problem in the past but did currently.

Mood was determined during the interview by asking individuals to rate their mood on a scale from one to 10 where one would be very depressed and 10 very happy. The distribution was distinctly skewed towards the upper end of the scale with a median rating of 7 .

Stressors were reported by $53.5 \%$ of the sample and the number ranged from 1-4. The 119 identified stressors were distributed among the following: work (30.3\%); spouse/child (16.8\%); finances (15.1\%); psychological $(12.6 \%)$; relationships $(8.4 \%)$; physical (7.6\%); parents (5.9\%); living arrangements $(2 \cdot 5 \%)$; and substance abuse $(0 \cdot 8 \%)$.

\section{Outcome measures}

The subjective measure of outcome was derived from the complaints by the respondents elicited during the interview when asked whether they had noted post-accident sequelae. The reported subjective sequelae were then categorised as physical, intellectual and emotional. The physical complaints were itemised in a systems schema. ${ }^{28}$ The intellectual complaints included difficulties with learning, memory, intellectual functioning and slowed thinking. The emotional complaints included anxiety, depressive and behavioural disorders and problems with selfesteem and feelings of rejection.

The details of the sequelae are itemised in table 5. Fifty individuals (31\%) reported 96 sequelae: 36 were physical, 30 intellectual and 30 emotional. The subjective sequelae were distributed as follows: $1-(17 \%), 2$ $-(8 \%), 3-(2 \%), 4-(2 \%), 5-(1 \%)$, and 7 $-(1 \%)$. The overlap of sequelae among the 50 individuals was: exclusively intellectual and/or emotional (27); intellectual and/or emotional as well as physical (11); and exclusively physical (12).

Of the 7 physical systems, the highest number of subjective sequelae were recorded under neurological, with two individuals reporting seizures: one is still on anti-convul- 
Table 5 Types of subjective sequelae $(n=50)$

\begin{tabular}{llc}
\hline System & Complaints & Frequency \\
\hline Physical & & \\
Neurological & Coordination or speed & 4 \\
& Seizures & 2 \\
& Handedness changed & 2 \\
& Dizziness & 1 \\
Musculo-skeletal & Speech & 1 \\
& Arthritis/osteoarthritis & 3 \\
& Back pain & 2 \\
Head and Neck & Leg/hip pain & 2 \\
& Leg shorter/deformity & 2 \\
Eyes & Headaches & 3 \\
& Plate area sensitive & 3 \\
Ears/Nose & Neck pain & 1 \\
Abdomen & Diplopia & 2 \\
Skin & Retinal damage & 1 \\
Intellectual & Fields/depth perception & 2 \\
& Tinnitus/sinusitis & 2 \\
& Kidney/spleen & 2 \\
& Sweating & 1 \\
Emotional & Learning problems/disabilities & 12 \\
Anxiety disorders & Memory/attention/concentration & 10 \\
Depressive disorders & Intelligence/brain affected & 4 \\
& Thinking/problem solving slowed & 4 \\
Self esteem problems & Anxieties, phobias, nightmares & 8 \\
Parent-child problems & Depression & 6 \\
Behaviour disorders & Depression with suicidal thoughts & 3 \\
& Insecure/self-conscious/introverted & 3 \\
\hline & Rejection by parent(s) & 5 \\
& Aggression (as child) & 2 \\
& Pyromania (as child) & 2 \\
\hline
\end{tabular}

sant medication and the seizures are currently controlled, whereas the other is not on medication and does not have a recent history of seizures. The second most frequent area of sequelae was derived from the musculoskeletal system, followed by sequelae regarding head and neck.

Among the intellectual sequelae, the most frequent complaint was difficulty in learning, followed by problems with memory or concentration, and in turn followed by statements that intelligence had been adversely affected, and finally a slowing of thought processes. Among the emotional sequelae, depression was the most frequent complaint. Three of those reporting depression indicated a history of accompanying suicidal ideation and two were currently experiencing suicidal thoughts. Anxiety disorders followed in terms of frequency, followed by problems with self esteem, then rejection by parents, and finally behaviour disorders (pyromania and aggression) during childhood.

There was a significant relationship (Kendall's Tau $0.19, \mathrm{p}<0.01$ ) between physical sequelae reported as directly related to the head injury and physical complaints identified as unrelated to the head injury. Specifically, $12.6 \%$ of the sample reported both physical sequelae and physical complaints unrelated to the trauma, $20 \cdot 1 \%$ reported physical sequelae but no physical complaints unrelated to the trauma, $18.9 \%$ reported no physical sequelae but physical complaints unrelated to the trauma, and $48.4 \%$ reported neither. These findings are understandable in view of the multiple injuries sustained by $26 \cdot 4 \%$ of the sample.

Relationships between extent of head injury and outcome

The first analysis evaluated the relationships between the trauma variables and subjective sequelae (physical, intellectual and emotional). Table 6 summarises the correlation matrix and as may be noted the composite measure was the most discriminating regarding long-term subjective sequelae. This in turn was followed by the neurological variable and seizures and finally fractures as predictors of sequelae. Unconsciousness was of limited predictive value and EEG was of no predictive value.

The second analysis evaluated the relationship between initial IQ and subjective sequelae, and the findings are also summarised in table 6. A comparison of those individuals who either reported or did not report sequelae in each of the three areas revealed significantly lower IQs for those with sequelae in both the intellectual and emotional areas.

The third analysis evaluated the relationship between attribute variables which purportedly relate to the outcome of head injury and the findings are summarised in table 7 . While only 3 of the 21 correlations were significant, this is greater than chance expectancy. Physical sequelae were significantly related to the agent of injury and subsequent litigation, and these are understandable. The relationships between intellectual sequelae and subsequent head injuries is also quite predictable.

The purpose of the fourth analysis was to determine whether the presence of subjective sequelae had any measurable effects upon objective and psychosocial measures of adaptation. The individuals reporting sequelae $(n=50)$ were therefore compared on designated demographic, health and psychosocial variables with individuals reporting no sequelae $(n=109)$. Significant differences were found in grade failures/retention $(40 \%$ for the sequelae group vs $19 \%$ for the non-sequelae group, $\left.\chi^{2}=6.65, \mathrm{p}<0.01\right)$, work status $(12 \%$ vs $2 \cdot 8 \%$ of unemployed respectively, $\left.\chi^{2}=3.89, \mathrm{p}<0.05\right)$, current psychological psychiatric problems $(32 \%$ vs $11.9 \%$ respectively, $\left.\chi^{2}=7.96, \mathrm{p}<0.01\right)$ and strained relationships with family members $(24 \%$ vs $15.6 \%$ respectively, $\left.\chi^{2}=3.95, p<0.05\right)$. No differences were found for past but resolved psychological/psychiatric problems, physical complaints, substance abuse or contact with legal authorities.

The fifth analysis dealt with continuity of complaints during the twenty three year interval between the original project and the current study. In the published five year follow up project, ${ }^{2}$ parents of the 117 children reported on average 0.89 complaints from the following: personality and mood, headaches and dizziness, memory and learning, sensorymotor, and fatigue and sleep. In the current study, the 159 adults reported on average 0.60 sequelae, and these were categorised as physical, intellectual and emotional. Of the 159 individuals included in the current study, 93 also had complaints in the initial project. The informants, however, were different as during the initial project information about complaints was provided by a parent, general- 
Table 6 Relationships between subjective sequelae and trauma variables as well as initial IQ (Kendall's Tau and t test)

\begin{tabular}{lccc}
\hline & \multicolumn{3}{l}{ Subjective sequelae } \\
\cline { 2 - 4 } Trauma variables & Physical & Intellectual & Emotional \\
\hline Unconscious & $0 \cdot 12$ & $0 \cdot 04$ & $0 \cdot 21^{\star \star}$ \\
Fracture & $0 \cdot 19^{\star \star}$ & $0 \cdot 20^{\star \star}$ & $0 \cdot 20^{\star \star}$ \\
EEG & $-0 \cdot 02$ & $0 \cdot 07^{\star \star}$ & $-0 \cdot 06$ \\
Neurological & $0 \cdot 13^{\star}$ & $0 \cdot 21^{\star \star}$ & $0 \cdot 35^{\star \star \star}$ \\
Seizures & $0 \cdot 20^{\star \star}$ & $0 \cdot 25^{\star \star}$ & $0 \cdot 18^{\star}$ \\
Composite & $0 \cdot 17^{\star \star \star}$ & $0 \cdot 23^{\star \star}$ & $0 \cdot 28^{\star \star \star}$ \\
Initial IQ & $-0 \cdot 05^{\star}$ & $-0 \cdot 21^{\star \star}$ & $-0 \cdot 17^{\star}$ \\
Initial IQ non-sequelae group & $103 \cdot 5$ & $104 \cdot 7$ & $104 \cdot 2$ \\
Initial IQ sequelae group & $99 \cdot 9$ & $93 \cdot 3$ & $98 \cdot 6$ \\
$t$ value & $1 \cdot 07$ & $3 \cdot 57^{\star \star}$ & $2 \cdot 37^{\star}$ \\
\hline
\end{tabular}

${ }^{\star} p<0.05^{\star \star} p<0.01{ }^{\star \star \star} p<0.001$

Table 7 Relationships between subjective sequelae and attribute variables (Kendall's Tau)

\begin{tabular}{lccc}
\hline & \multicolumn{3}{l}{ Subjective sequelae } \\
\cline { 2 - 4 } Attribute variables & Physical & Intellectual & Emotional \\
\hline Pre-morbid & 0.00 & 0.06 & -0.07 \\
Sex & 0.05 & 0.04 & 0.12 \\
Age (trauma) & -0.08 & 0.06 & 0.04 \\
Age (current) & 0.05 & -0.01 & 0.04 \\
Injury agent & $0.16^{\star}$ & 0.03 & 0.05 \\
Litigation & $0.28^{\star \star \star}$ & 0.08 & 0.11 \\
Subsequent head injury & -0.01 & $0.22^{\star \star \star}$ & 0.06 \\
\hline
\end{tabular}

${ }^{\star} \mathrm{p}<0.05^{\star \star} \mathrm{p}<0.01{ }^{\star \star \star} \mathrm{p}<0.001$

ly the mother, whereas during the current study information about sequelae was provided by the volunteers. Furthermore, the categories of complaints in the five year follow up project were different from the sequelae in the current study. Granted the methodological differences of the original project and the current study, the data were analysed to determine whether a trend existed. A comparison of the presence or absence of complaints in the original project with the presence or absence of sequelae in the current study revealed a significant relationship (Kendall's Tau 0.19, p < 0.02).

\section{Discussion}

There are no published reports which document the natural history of recovery from head injuries in children into adulthood and certainly none which extend to 23 years after the head injury. This study has demonstrated the feasibility of conducting a very long-term outcome study of children who initially sustained primarily mild head injuries, with about $10 \%$ of the group having suffered a moderate or severe head injury. In some instances, the interviewer had the distinct impression that individuals were underreporting or minimising effects. For example, while 10 individuals with a history of posttraumatic seizures in the original project were interviewed in the follow up study, only 2 of the respondents reported the presence of seizures in the past or at present. Denial seems to be the most viable explanation. It should be emphasised that intervening life events between the initial project and the current study would have an interactive effect on long-term outcome, but the model of such interaction is complex. The health data included as an intervening variable are not intended to reflect the complexity of life events but only to sample the more obvious areas. Finally, there was no discernable difference among those individuals reporting sequelae and the interview format (in person or by telephone).

Given these caveats, the cardinal findings of this study were: 1) Subjective sequelae were reported by $31 \%$ of the sample; 2) These subjective sequelae were related to the extent of head injury, initial IQ and current measures of social adaptation. The findings regarding unconsciousness, skull fractures and EEG are consistent with published predictive validity studies. ${ }^{529}$ In addition to the neurological variables as predictors of outcome, IQ recorded in the post-acute phase was found to be a reliable predictor of longterm outcome. These relationships could not be explained by pre-morbid variables such as age, sex and developmental anomalies.

This absence of a relationship between attribute variables of age, sex and pre-morbid factors with outcome is consistent with some publications, ${ }^{30-32}$ but not all. ${ }^{33-34}$ The incidence of $15 \cdot 1 \%$ of recurrent head injuries reported in this study is consistent with a recent publication ${ }^{35}$ which reported recurrent brain injury rates that ranged from $4.3 \%$ to $40 \%$.

The documented relationships between the presence of subjective sequelae and designated objective and psychosocial measures of adaptation including educational lag, a higher unemployment rate, current psychological/ psychiatric problems and strained relationships with family members further our understanding of the long-term effects of significant head injury in children.

The rate of unemployment in the current study was significantly less than reported in other publications. ${ }^{15-17}$ Specifically, $3 \cdot 8 \%$ of the sample was unemployed while the base rate of unemployment for ages 25 or older in this geographic locale is $7 \cdot 7 \%$. The low rates of unemployment in this study may accordingly be related to the inherent characteristics of the sample. For example, IQ was at the 77th percentile at the last follow up of the five year project. Furthermore, in the current study educational attainment and occupational level were skewed as $42 \cdot 1 \%$ of the sample had tertiary vocational professional training or university degrees while $27 \cdot 1 \%$ reported their occupations as professional or semi-professional. Notwithstanding the demographic characteristics of the study sample, unemployment for those with sequelae was four times higher than those without. The actual rate of unemployment in studies of head injury should accordingly be interpreted in a broader context and in addition to the extent of the head injury and sequelae should take into account factors such as IQ, educational attainment, occupational status and work stability.

The natural history of recovery from a head injury in children was outlined in the five year follow up publication. ${ }^{2}$ Specifically, there were immediate and very pronounced neurological, neuropsychological and EEG effects, these effects decreased considerably 
so that by the fifth follow up a majority of the children had improved substantially. With respect to the reconstitution process, the question posed initially was whether this was a function of the severity of head injury, individual differences in disposition, subsequent environment or an interaction of these variables. Based on the long-term findings of the current study, individual differences in disposition have not been identified as particularly relevant. Intervening life events while inordinately complicated are undoubtedly interactive, but with the available information it is not possible to go beyond this statement. However, the severity of the head injury has been identified as the primary contributory factor in the reconstitution process. The current study extends this relationship in the prediction of even long term outcomes. Furthermore, the presence of long term subjective sequelae is consistent with objective indicators of social adaptation. This research was supported by the Insurance Corporation of
British Columbia, British Columbia, Canada. We wish to British Columbia, British Columbia, Canada. We wish to
express our appreciation to Mrs Vinetta Lunn for her creative express our appreciation to Mrs Vinetta Lunn for her creative
approach in tracing individuals and invaluable assistance, to approach in tracing individuals and invaluable assistance, to
$\mathrm{Mr}$ Don Gilbert for his consistent support, and to Mrs Mary Klonoff for assisting with the manuscript.

1 Klonoff $\mathrm{H}$, Paris $\mathrm{R}$. Immediate short-term and residual effects of acute head injuries in children. In: Reitan R, Davison LA, eds. Clinical neuropsychology: current status and applications. Washington: Winston, 1974:179-210.

2 Klonoff H, Low MD, Clark C. Head injuries in children: a prospective five year follow-up. $\mathcal{f}$ Neurol Neurosurg Psychiatry 1977;40:1211-9.

3 Levin HS, Grafman J, Eisenberg HM, eds. Neurobehavioral recovery from head injury. New York: Oxford University Press, 1987.

4 Levin HS, Benton AL, Grossman RG. Neurobehavioral consequences of closed head injury. New York: Oxford University Press, 1982

5 Levin HS, Eisenberg HM, Benton AL, eds. Mild head injury. New York: Oxford University Press, 1989.

6 Jennett B, Teasdale G. Management of head injuries. Philadelphia: FA Davis, 1981

7 McLean A, Dikmen S, Temkin N, et al. Psychosocial functioning at one month after head injury. Neurosurgery 1984;14:393-9.

8 Klonoff PS, Snow WG, Costa LD. Quality of life in patients two to four years after closed head injury. patients two to four years afte
Neurosurgery 1986;19:735-43.

9 Thomsen IV. Late outcome of very severe blunt head trauma: a $10-15$ year second follow up. $f$ Neurol trauma: a $10-15$ year second fo
Neurosurg Psychiatry $1984 ; 47: 260-8$.

10 Oddy M, Coughlan T, Tyerman A, et al. Social adjustment after closed head injury: A further follow-up seven years after injury. $\mathcal{f}$ Neurol Neurosurg Psychiatry 1985;48:564-8.
11 Costeff H, Groswasser Z, Goldstein R. Long-term followup review of 31 children with severe closed head trauma. 7 Neurosurg 1990;73:684-7.

12 Tate RL, Fenelon B, Manning ML, et al. Patterns of neuropsychological impairment after severe blunt head injury. F Nerv Ment Dis 1991; 179:117-26.

13 Lishman WA. Brain damage in relation to psychiatric disability after head injury. $\mathrm{Br} F$ Psychiatry 1968 114:373-410.

14 Levin HS, Grossman RG. Behavioral sequelae of closed head injury: a quantitative study. Arch Neurol 1978;35 $720-6$.

15 Rimel RW, Giordani B, Barth JT, et al. Moderate head injury: completing the clinical spectrum of brain trauma. Neurosurgery $1982 \cdot 11: 344-51$.

16 McKinlay WW, Brooks DN, Bond MR. Post-concussional symptoms, frooks DN, Bond MR. Post-concussionsevere blunt head injury. F Neurol Neurosurg Psychiatry' 1983;46:1084-91.

17 Kreutzer JS, Wehman PH, Harris JA, et al. Substance abuse and crime patterns among persons with traumatic brain injury referred for supported employment. Brain Inj 1991;5:177-87.

18 Lewin W, Marshall TF, Roberts AH. Long-term outcome after severe head injury. $B M \mathcal{F}$ 1979;2:1533-8.

19 Rimel RW, Jane JA. Characteristics of the head-injured patient. In: Rosenthal M, Griffith ER, Bond MR Miller JD, eds. Rehabilitation of the head-injured adult. Phila: FA Davis, 1983:9-21.

20 Levin HS, Gary HE, Eisenberg HM, et al. Neurobehavioral outcome one year after severe head injury. § Neurosurg 1990;73:699-709.

21 Eiben C, Anderson T, Lockman L, et al. Functional outcome of closed head injury in children and young come of closed head injury in children and

22 Mahoney WJ, D'Souza BJ, Haller JA, et al. Long-term outcome of children with severe head trauma and prolonged coma. Pediatrics 1983;71:756-62.

23 Alberico AM, Ward JD, Choi SC, et al. Outcome after severe head injury: relationship to mass lesions, diffuse injury and ICP course in pediatric and adult patients. f Neurosurg 1987;67:648-56

24 Berger MS, Pitts LH, Lovely $M$, et al. Outcome from severe head injury in children and adolescents. Neurosurg 1985;62:194-9.

25 Levati A, Farina ML, Vecchi G, et al. Prognosis of severe head injuries. $\mathcal{F}$ Neurosurg 1982;57:779-83.

26 Jennett $B$, Bond $M$. Assessment of outcome after severe brain damage. Lancet 1975;1:480-4.

27 Hendryx PM. Psychosocial changes perceived by closedendryx PM. Psychosocial changes perceived by closed-
head-injured adults and their families. Arch Phys Med head-injured adults and

28 Seidel HM, ed. Mosby's guide to physical examination, 2nd ed. St Louis: Mosby Year Book, 1991.

29 Edna TH, Cappelen J. Late postconcussional symptoms in traumatic head injury: An analysis of frequency and risk factors. Acta Neurochir 1987;86:12-7.

30 Klonoff $\mathrm{H}$. Head injuries in children: predisposing factors, accident conditions, accident proneness and sequelae. Am 7 Public Health 1971;61:2405-17.

31 Chadwick O, Rutter M, Shaffer D, et al. A prospective study of children with head injuries. IV: Specific cognitive defects. F Clin Neuropsychol 1981;3:101-20.

32 Kraus JF, Fife D, Cox P, et al. Incidence, severity and external causes of pediatric brain injury. $A m \mathcal{F}$ Dis Child 1986;140:687-93.

33 Annegers JF. The epidemiology of head trauma in children. In: Shapiro K, ed. Pediatric head trauma. New Yren. In: Shapiro K, ed. Pediatric

34 Fabian AA, Bender L. Head injury in children: predisposng factors. Am f Orthopsychiatry 1947;17:68-79.

35 Salcido R, Costich JF, Conder $\tilde{R}$, et al. Recurrent severe traumatic brain injury: series of six cases. Amer $\mathcal{F}$ Phys Med Rehabil 1991;70:215-9. 